\title{
ABSORÇÃO DE MANGANÊS EM SOJA RR SOB EFEITO DO GLIFOSATE ${ }^{(1)}$
}

\author{
Gabriel José Massoni de Andrade ${ }^{(2)} \&$ Ciro Antonio Rosolem ${ }^{(3)}$
}

\begin{abstract}
RESUMO
Foi levantada a hipótese de que o glifosate aplicado à soja resistente ao herbicida poderia alterar a eficiência de absorção e translocação do nutriente na planta. Com o objetivo de estudar o acúmulo e distribuição do $\mathrm{Mn}$, assim como a cinética de absorção de Mn pela soja geneticamente modificada sob efeito da aplicação de glifosate, foram conduzidos dois experimentos. No primeiro, os tratamentos foram constituídos por duas cultivares de soja quase isogênicas cultivadas em solução nutritiva (Conquista e Valiosa $R R$ com aplicação ou não do herbicida). As concentrações de Mn empregadas na solução nutritiva foram: 0; 0,085; 0,125; 0,250; e 0,500 $\mathrm{mg} \mathrm{L}^{-1}$. Após 25 dias de cultivo, parte do total de plantas de soja transgênica foi pulverizada com o herbicida. No segundo experimento, para avaliação da cinética de absorção do Mn da cultivar Valiosa RR, as plantas foram pulverizadas com glifosate aos 26 dias de cultivo nas doses de 0,15 e $960 \mathrm{~g} \mathrm{ha}^{-1} \mathrm{e} . \mathrm{a}$. Constatou-se que a transgenia para resistência ao herbicida não altera a nutrição mangânica na cultivar de soja Valiosa RR. Mesmo reduzindo a massa de matéria seca de raiz, o glifosate não interfere na absorção e no transporte de Mn na planta de soja transgênica. Quanto à absorção do Mn pela cultivar transgênica, os

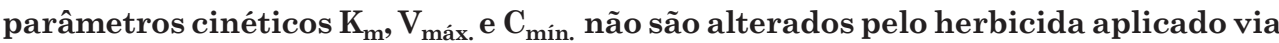
foliar.
\end{abstract}

Termos de indexação: Glycine max L., cinética de absorção, micronutrientes e nutrição mineral de plantas.

\footnotetext{
(1) Parte da Dissertação de Mestrado do primeiro autor apresentada à Faculdade de Ciências Agronômicas da UNESP/Botucatu. Financiado pela Fapesp. Recebido para publicação em setembro de 2010 e aprovado em março de 2011.

${ }^{(2)}$ Mestrado em Agronomia-Agricultura pelo Departamento de Produção Vegetal - Faculdade de Ciências Agronômicas - UNESP. Caixa Postal 237, CEP 18603-970 Botucatu (SP). E-mail: agrobiel@yahoo.com.br

${ }^{(3)}$ Professor do Departamento de Produção Vegetal, Faculdade de Ciências Agronômicas, UNESP. Bolsista do CNPq. E-mail: rosolem@fca.unesp.br
} 


\title{
SUMMARY: UPTAKE OF MANGANESE IN RR SOYBEAN UNDER GLIFOSATE APPLICATION
}

\begin{abstract}
It was hypothesized that Mn uptake efficiency and transport by transgenic, glifosateresistant soybean would be affected by application of the herbicide. Two experiments were carried out to study manganese uptake, long-distance transport and absorption kinetics of genetically modified soybean as affected by glifosate application. Experiment 1: The treatments consisted of two near-isogenic soybean cultivars grown in nutrient solution (Conquista and Valiosa RR with or without application of glifosate). The Mn levels in the nutrient solution were 0, 0.085, 0.125, 0.250, $0.500 \mathrm{mg} \mathrm{L}^{-1}$. Twenty-five days after emergence, part of the total transgenic soybean plants were sprayed with herbicide. Experiment 2: Plants were sprayed with glifosate on the $26^{\text {th }}$ day of cultivation at rates of 0 (zero), 15 and $960 \mathrm{~g} \mathrm{ha}^{-1}$ to study the Mn absorption kinetics of cultivar Valiosa RR. It was found that genetic resistance to glifosate did not affect manganese nutrition in soybean cultivar Valiosa RR. Despite reducing the root dry matter, glifosate does not hamper Mn absorption and transport in transgenic soybean plants. The Mn absorption kinetic parameters of Valiosa $R R, K_{m}, V_{\max }$ and $C_{\min }$ are not altered by glifosate applied to leaves.
\end{abstract}

Index terms: Glycine $\max$ L., absorption kinetics, micronutrients and plant nutrition.

\section{INTRODUÇÃO}

O Mn é essencial na síntese de clorofila e sua função principal está relacionada à ativação de enzimas (Dechen \& Nachtigall, 2006); o papel mais bem documentado e exclusivo do Mn em plantas verdes é na reação de Hill (Marschner, 1995). Ainda, o Mn atua como um importante cofator para várias enzimaschave na biossíntese dos metabólitos secundários da planta associados com a via do ácido chiquímico. Como o herbicida glifosate também age no metabolismo do ácido chiquímico, há relatos de que as plantas de soja RR (Roundup Ready) seriam menos eficientes no acúmulo de Mn que as convencionais (Gordon, 2007; Huber, 2007). Entretanto, poucos trabalhos têm sido desenvolvidos usando-se plantas resistentes ao glifosate, permanecendo a dúvida sobre se esses efeitos ocorreriam nessas plantas.

A deficiência de Mn em soja caracteriza-se pelo desenvolvimento de clorose internerval em folhas novas, com teores do nutriente entre 10 e $20 \mathrm{mg} \mathrm{kg}^{-1}$ (Malavolta et al., 2000). Por outro lado, embora a soja resistente ao glifosate $(\mathrm{RR})$ não seja severamente afetada, o herbicida leva à diminuição do teor de clorofila (Hoagland, 1980), resultando em crescimento clorótico das plantas quando expostas a doses subletais (Wong, 2002), o que pode ser confundido com a deficiência de Mn.

A soja resistente ao herbicida glifosate corresponde a aproximadamente $76 \%$ da área cultivada com transgênicos no Brasil (Isaaa, 2009). O glifosate é absorvido e translocado nas plantas, promovendo eficiente controle das plantas daninhas nos estádios em que a competição seria extremamente negativa para a cultura. Contudo, existem relatos de diferentes efeitos fisiológicos induzidos por esse herbicida (Reddy et al., 2004). Por exemplo, tem sido relatada a diminuição na absorção e transporte do Mn em plantas não alvo (Römheld et al., 2005; Neumann et al., 2006). Um dos processos de interferência relatados é a formação de um complexo pouco solúvel e móvel entre o glifosate e íons cationicos (Eker et al., 2006), porém a natureza desse antagonismo não é bem conhecida. Além disso, o acumulo de glifosate nas raízes pode resultar na formação de um complexo imóvel de Fe e Mn, com o herbicida limitando dessa maneira o transporte desses nutrientes (Feng et al., 2003).

Zobiole et al. (2010) concluíram que a recomendação de adubação para soja RR deveria considerar a diminuição de eficiência imposta pelo uso do herbicida, mas o problema é que esses autores não determinaram a eficiência de uso de Mn pela soja. Além disso, o efeito do gen ou da aplicação de glifosate não foi generalizado para todas as cultivares e solos estudados. Há de se considerar ainda que, neste experimento, os teores de Mn nas folhas foram muito altos, de modo que o decréscimo observado na produção de matéria seca não pode ser atribuído ao herbicida. Por outro lado, em experimento específico para o estudo do efeito do Mn na nutrição da soja, não foram encontradas evidências de efeitos negativos do glifosate na absorção, acumulação, distribuição do Mn na soja e na resposta da planta ao Mn (Rosolem et al., 2010).

Este trabalho foi baseado nas seguintes hipóteses: o uso de glifosate na soja RR poderia prejudicar a absorção e, ou, a distribuição do Mn na planta, podendo induzir sua deficiência, e a inclusão do gene da resistência tornaria cultivares de soja $R R$ menos eficientes no acúmulo deste micronutriente. Assim, objetivou-se estudar o acúmulo e a distribuição do Mn, 
bem como a cinética de sua absorção pela soja transgênica sob efeito da aplicação de glifosate via foliar.

\section{MATERIAL E MÉTODOS}

Foram desenvolvidos dois experimentos em casa de vegetação no Departamento de Produção Vegetal da Faculdade de Ciências Agronômicas, UNESPBotucatu.

\section{Experimento 1: Acúmulo e distribuição de Mn na planta}

Neste experimento foram cultivadas uma variedade convencional e uma transgênica, sendo que a transgência recebeu ou não aplicação foliar de glifosate, com o objetivo de testar o efeito da introdução do gene e também da aplicação do herbicida à planta transgênica sobre a absorção e o transporte de Mn na planta.

Sementes de soja foram tratadas com fungicida de contato Captan e colocadas para germinar a $25^{\circ} \mathrm{C}$. As plântulas foram selecionadas quanto à sanidade $\mathrm{e}$ uniformidade após cinco dias. No oitavo dia, estádio fenológico VE (Fehr \& Caviness, 1977), as plântulas foram transferidas para vasos plásticos (pintados na cor branca) contendo $6 \mathrm{~L}$ de solução nutritiva (Hoagland \& Arnon, 1950), modificada quanto à concentração de Mn.

Para evitar injúrias às plântulas, na primeira semana a solução empregada foi diluída a 1/10; na segunda semana, a solução a $1 / 2$; e a partir da terceira semana usou-se a solução completa. A solução foi aerada constantemente e trocada semanalmente, com variação máxima de $5 \%$ do volume. Foram cultivadas duas plantas de soja por vaso. $\mathrm{O}$ pH da solução foi monitorado a cada dois dias e corrigido, quando necessário, a 5,5, através da adição de $\mathrm{HCl}$ ou $\mathrm{NaOH}$ $0,1 \mathrm{~mol} \mathrm{~L}^{-1}$. A temperatura da solução foi monitorada e não ultrapassou $30^{\circ} \mathrm{C}$, e a temperatura média da casa de vegetação foi de $21,7^{\circ} \mathrm{C}$. As concentrações de $\mathrm{Mn}^{2+}$ foram: 0,000; 0,085; 0,125; 0,250; e 0,500 $\mathrm{mg} \mathrm{L}^{-1}$.

Foram utilizadas as cultivares de soja convencional Conquista e sua "quase isogênica" transgênica Valiosa RR sem aplicação de glifosate, além da Valiosa RR com aplicação do glifosate via foliar. No tratamento com soja transgênica e glifosate, as plantas foram submetidas à aplicação de $720 \mathrm{~g} \mathrm{ha}^{-1}$ (e.a.), utilizando produto formulado à base do sal isopropilamina. A aplicação foi realizada 25 dias após o início da condução do experimento, com a soja no estádio V4/V5 (Fehr \& Caviness, 1977). A pulverização foi feita com as plantas fora da casa de vegetação, com pulverizador costal pressurizado $\left(\mathrm{CO}_{2}\right)$ equipado com ponta de pulverização DG TEEJET 110-02 com volume de calda de $200 \mathrm{~L} \mathrm{ha}^{-1}$. Após a pulverização, as plantas foram retornadas à casa de vegetação e mantidas isoladas das demais durante um período superior a $6 \mathrm{~h}$. Aos
15 dias após a aplicação do herbicida, as plantas foram coletadas, separadas em folhas, hastes (caule mais ramos) e raízes e secas em estufa de circulação forçada, a $60^{\circ} \mathrm{C}$ por $48 \mathrm{~h}$. Determinou-se, então, massa de matéria seca, e os tecidos vegetais foram moídos em moinho tipo Wiley e submetidos à digestão em solução ácida nítrico-perclórica (Malavolta et al., 1997). Posteriormente, efetuou-se a leitura dos extratos usando um espectrofotômetro de absorção atômica. Foi calculado o valor da eficiência de absorção pela fórmula: E.A. $=($ miligrama do nutriente na planta/grama de massa da matéria seca de raiz).

O delineamento utilizado foi o de blocos completos ao acaso, em esquema fatorial $5 \times 3$, com quatro repetições. Foi feita a análise de variância dos dados originais. Quando detectada variação significativa entre cultivares, as médias foram comparadas usando o teste t LSD $(p<0,05)$. Equações de regressão foram ajustadas para as concentrações de $\mathrm{Mn}$, quando pertinente.

\section{Experimento 2: Cinética de absorção}

Neste experimento, procurou-se entender o efeito do glifosate na cinética de absorção de Mn por uma variedade resistente ao herbicida.

Sementes de soja da cultivar Valiosa RR foram germinadas e selecionadas nas mesmas condições do experimento anterior. No oitavo dia, VE (Fehr \& Caviness, 1977), transferiram-se quatro plântulas para os vasos plásticos, também pintados de branco. Foram cultivadas três plantas em $3,5 \mathrm{~L}$ de solução nutritiva de Hoagland \& Arnon (1950). O manejo e as trocas da solução nutritiva seguiram os mesmos procedimentos já descritos para o experimento 1 . Aplicou-se o glifosate aos 26 dias de cultivo, estádio V4/V5 (Fehr \& Caviness, 1977), com vazão, equipamento, formulação e procedimentos idênticos aos do experimento anterior. As doses utilizadas foram: 0, 15 e $960 \mathrm{~g} \mathrm{ha}^{-1}$ e.a. No segundo dia após a aplicação do herbicida, toda a solução nutritiva foi trocada por outra sem Mn. Nessa operação, os vasos e as raízes foram lavados com água deionizada corrente. As plantas foram mantidas por $48 \mathrm{~h}$ na condição de ausência de Mn. Posteriormente, outra solução nutritiva foi adicionada num volume de $3 \mathrm{~L}$, incluindose agora o Mn na concentração de $0,25 \mathrm{mg} \mathrm{L}^{-1}$. O volume da solução nutritiva foi mantido constante durante todo o período experimental. No estudo da cinética de absorção utilizou-se a técnica de esgotamento da solução, de acordo com Claassen \& Barber (1974). As coletas das amostras de solução foram iniciadas $30 \mathrm{~min}$ após a adição do Mn. Nessa operação, tomaram-se alíquotas de $5 \mathrm{~mL}$ aos 0,60 , $120,180,240,360,480,600,900$ e $1.440 \mathrm{~min}$. A temperatura média da casa de vegetação durante todo o período experimental foi de $20,8^{\circ} \mathrm{C}$. A temperatura da solução durante o experimento de exaustão permaneceu entre 22 e $28^{\circ} \mathrm{C}$. Após este experimento, as plantas foram coletadas e divididas em folhas, 
hastes e raízes. A determinação de massa de matéria seca e a análise química das plantas seguiram o mesmo procedimento e método do experimento anterior.

As leituras nas alíquotas da solução de exaustão foram feitas usando um espectrofotômetro de absorção atômica.

Os dados da concentração de Mn na solução de exaustão, em cada tempo de amostragem, foram utilizados para calcular os parâmetros cinéticos. Os valores de $\mathrm{K}_{\mathrm{m}}$ e $\mathrm{V}_{\text {máx }}$ foram obtidos considerando-se a massa de matéria seca radicular como base de cálculo. Os valores da taxa de influxo foram calculados com base na quantidade ( $\mu \mathrm{mol})$ de Mn absorvido pela planta em relação à unidade de massa de matéria seca de raiz, mediante a utilização de aproximação gráficomatemática (Ruiz, 1985). O C $\mathrm{C}_{\text {mín }}$ foi estimado pela média dos valores da concentração de Mn na solução de exaustão, a partir do ponto em que permaneceram constantes, ou seja, foi considerado como a concentração de Mn nas amostras de solução após 34 h do início do período das amostragens (Claassen \& Barber, 1974).

O delineamento foi em blocos completos ao acaso, constituído por três tratamentos (doses de glifosate) e sete repetições. Foi realizada análise de variância dos dados originais e aplicação do teste t LSD $(p<0,05)$ para as médias obtidas.

\section{RESULTADOS E DISCUSSÃO}

Quanto ao acúmulo de Mn nas folhas e hastes, houve efeito principal das doses desse nutriente na solução ( $p<0,0001)$, de modo que a soja respondeu de forma quadrática à concentração de Mn na solução, apresentando sintomas característicos de deficiência no nível zero do elemento na solução nutritiva. Mesmo havendo efeito principal do nível de Mn, optou-se por ilustrar o comportamento das cultivares, e foi verificado que, nesses dois casos (Figura 1a,b), não houve efeito da inclusão do gene da resistência, ou seja, o acúmulo de Mn da cultivar transgênica não diferiu do da convencional, diferentemente do que havia sido observado por Gordon (2007). Além disso, a presença do herbicida não alterou o acúmulo de Mn nas folhas e nas hastes da soja transgênica. Ainda assim, é interessante destacar que, para o teor de Mn nas hastes, as plantas transgênicas tratadas com glifosate apresentaram aumento significativo ( $p<0,0001)$, independentemente da concentração de Mn na solução, sendo os valores do teor de 23, 20 e $29 \mathrm{mg} \mathrm{kg}^{-1}$, respectivamente para Conquista, Valiosa RR e Valiosa RR com glifosate.

Outros autores também haviam verificado que os teores de Mn, e de outros nutrientes, de uma cultivar de soja transgênica não foram alterados pelo glifosate formulado à base de sal de isopropilamina ou de sal potássico (Santos et al., 2007). Da mesma forma,
Broch \& Ranno (2008) não verificaram danos do glifosate na nutrição de Mn da soja, porém Zobiole et al. (2009) constataram redução nos teores de Zn, Mn, $\mathrm{Fe}, \mathrm{Cu}$ e B em uma cultivar de maturação precoce, BRS 242 RR, tanto pela inclusão do gene da resistência como pela ação do herbicida glifosate (aplicação única ou sequencial de $1.200 \mathrm{~g} \mathrm{ha}^{-1}$ de e.a. do glifosate). As cultivares do grupo de maturação médio (BRS $245 \mathrm{RR}$ ) e tardio (BRS $247 \mathrm{RR}$ ) não apresentaram redução no teor de Mn em função do gene da resistência, e sim quando as plantas foram tratadas com o glifosate. Zobiole et al. (2009) comentam ainda que essas diferenças entre as reduções no teor de nutrientes em cultivares transgênicas, provavelmente, estejam relacionadas com o grupo de maturação em que estão classificadas. No caso desses autores, a cultivar de maturação precoce teve maior redução nos teores de nutrientes sob influência do gene da resistência ao glifosate. Dessa forma, no presente experimento, a inexistência de modificações na nutrição do Mn das cultivares Conquista e Valiosa $R R$ poderia ser explicada pelo fato de pertencerem ao grupo de maturação semitardio.

A interação significativa para os acúmulos de Mn nas raízes $(\mathrm{p}<0,0003)$ e total $(\mathrm{p}<0,0152)$ indica que as cultivares foram influenciadas pelas concentrações de Mn. Observa-se (Figura 1c) que todas as cultivares apresentaram aumento linear nos acúmulos radiculares de Mn. Entretanto, a cultivar Valiosa $\mathrm{RR}$ acumulou maior quantidade de Mn que os outros dois tratamentos no nível de 0,50 $\mathrm{mg} \mathrm{L}^{-1}$ de Mn. Constatou-se (Figura 1d) que o acúmulo total seguiu padrão muito semelhante ao observado nas raízes. No acúmulo total de Mn, a cultivar Conquista apresentou resposta quadrática com máximo acúmulo estimado de 4,38 mg/vaso na concentração estimada de 0,49 $\mathrm{mg} \mathrm{L}^{-1}$ de Mn. A cultivar Valiosa RR com e sem glifosate apresentou resposta linear; no maior nível de Mn na solução, a cultivar transgênica tratada com glifosate apresentou menor acúmulo: aproximadamente $44 \%$ menos $\mathrm{Mn}$ que o acumulado nela sem o herbicida (Figura 1d). O acúmulo total de Mn da cultivar Valiosa RR também foi maior que o da Conquista na maior dose de Mn. Bott et al. (2008) observaram maior acúmulo de Mn na cultivar Valiosa RR em comparação a Conquista e, dessa maneira, comentaram que esta última absorveria mais Mn que a convencional numa condição de maior suprimento do micronutriente. Entretanto, Bott et al. (2008) constataram somente o acúmulo de Mn nas folhas, ao passo que os resultados deste trabalho mostram que não houve diferença no acúmulo de Mn nas folhas, e sim nas raízes. É válido destacar que a concentração de Mn considerada adequada nos experimentos de Bott et al. (2008) corresponde a 0,027 $\mathrm{mg} \mathrm{L}^{-1}$ de Mn, muito abaixo de $0,50 \mathrm{mg} \mathrm{L}^{-1}$ de $\mathrm{Mn}$, na qual ocorreu diferença no presente estudo.

Neste estudo não foram constatadas alterações conclusivas que confirmassem o efeito depressor do 

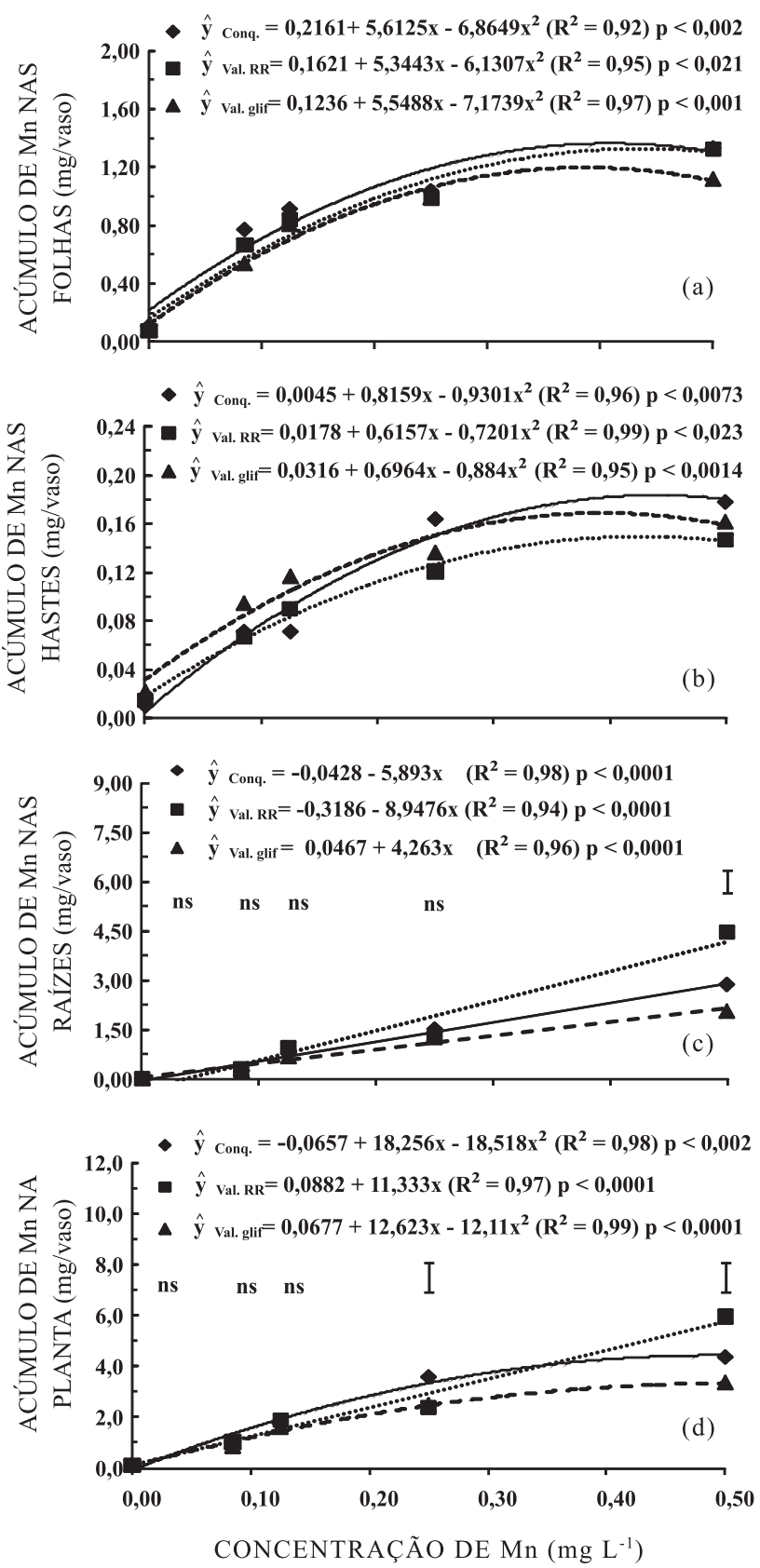

Figura 1. Acúmulo de Mn em folhas (a), hastes (b), raízes (c) e total na planta (d) por soja das cultivares Conquista e Valiosa RR com ou sem aplicação de glifosate via foliar, em função de doses de Mn na solução nutritiva. Barra vertical representa o valor do DMS pelo teste t a $5 \%$.

glifosate, tanto na absorção do Mn quanto no transporte do nutriente para as demais partes da planta. É válido ressaltar o aumento no teor de Mn nas hastes das plantas transgênicas tratadas com glifosate, porém, mesmo assim, não houve alterações no acúmulo de Mn das outras partes da planta. É possível a formação de um complexo estável entre o glifosate e o Mn (Coutinho \& Mazo, 2005), o que limitaria a absorção e transporte do elemento na planta (Eker et al., 2006). Segundo Feng et al. (2003), o glifosate absorvido pelas folhas é transportado na planta e acumulado nas raízes e partes jovens, e a acumulação na raiz poderia alterar negativamente o transporte de elementos metálicos, como Fe e Mn. A possibilidade para eventual redução no teor de manganês seria de que o glifosate, considerado um ácido fosfônico (Franz et al., 1997), funcionasse como "quelatizante" de cátions metálicos (Kabachnik et al., 1974), podendo formar quelatos com cátions bi e trivalentes.

No presente experimento, por ocasião da aplicação do glifosate à base do sal isopropilamina, foram observados sintomas de injúrias nas folhas, caracterizadas por pequenas manchas necróticas e irregulares. Os sintomas ficaram restritos às folhas que interceptaram o jato de pulverização; as folhas novas, emitidas após a aplicação, não apresentaram sintomas. Há relatos de que a injúria nas folhas esteja associada à presença do adjuvante aminado na formulação do produto comercial (Correia \& Durigan, 2007); contudo, segundo Reddy \& Zablotowicz (2003), a injúria poderia ocorrer em função do sal de glifosate, de surfatantes ou ainda de outro ingrediente na formulação do glifosate. O glifosate diminui o conteúdo da clorofila em hipocótilos e em folhas de soja no campo (Hoagland, 1980), o que pode ser confundido com deficiência de Mn. Foi sugerido que esse seria um efeito de um metabólito formado na degradação do glifosate, o AMPA (Amino-methylphosphonic acid), uma vez que as injúrias são dependentes do nível de AMPA formado na planta, do genótipo, de condições ambientais e da dose do glifosate (Reddy et al., 2004). Essas injúrias, ou fitointoxicação, foram observadas em campo no Centro-Oeste brasileiro, porém sem efeito na nutrição mangânica e na produção da soja (Broch \& Ranno, 2008), da mesma forma que no presente experimento.

A análise de variância revelou efeito principal dos níveis de Mn para a produção de massa de matéria seca (MMS), para o total ( $p<0,0001)$ e para as partes da planta: folhas e raízes $(p<0,0001)$ e hastes $(p<0,0003))$. A produção de matéria seca total da planta (Figura 2a) atingiu pico no nível de $0,085 \mathrm{mg} \mathrm{L}^{-1}$, para as cultivares Conquista e Valiosa RR. Heenan \& Carter (1976) consideraram que a concentração de 0,097 $\mathrm{mg} \mathrm{L}^{-1}$ de Mn na solução nutritiva foi ótima para o desenvolvimento de quatro cultivares de soja.

Em todos os casos, a inclusão do gene da resistência não alterou o crescimento e desenvolvimento das plantas, assim como, exceto para as raízes, o herbicida não teve influência na produção de MMS. Resultados semelhantes foram encontrados por Correia \& Durigan (2007), os quais utilizaram dose de $1,2 \mathrm{~kg} \mathrm{ha}^{-1}$ de e.a. de glifosate de vários produtos comerciais e constataram que esses herbicidas não influenciaram o desenvolvimento vegetativo e reprodutivo das plantas de soja geneticamente modificada (GM). 


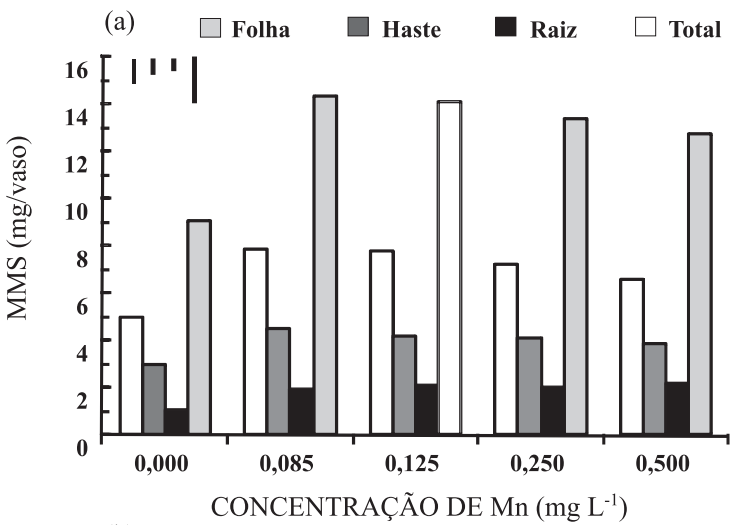

(b)

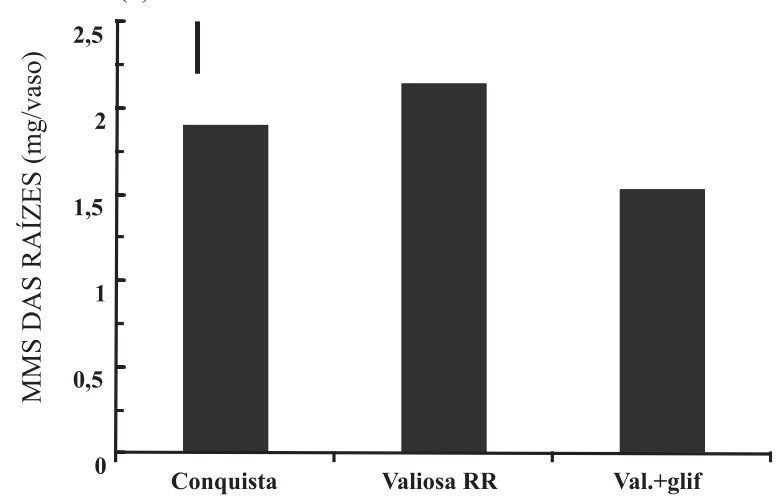

Figura 2. Produção de massa de matéria seca de folhas, hastes, raízes e total em função de doses de Mn na solução nutritiva (a) e produção de massa de matéria seca de raízes em função de variedades e aplicação de glifosate (b). Barras verticais representam o valor do DMS pelo teste t a $5 \%$.

A produção de MMS de raízes apresentou também efeito principal de cultivares $(\mathrm{p}<0,0005)$ e foi alterada negativamente pelo herbicida, independentemente do nível de Mn adicionado à solução nutritiva (Figura $2 b$ ). O decréscimo foi de $28,8 \%$ em relação à produção de matéria seca de raiz da cultivar transgênica não tratada com o herbicida. Há evidências de que o efeito fitotóxico do AMPA (Aminomethylphosphonic acid) seja o responsável pela redução do crescimento da planta GM e do conteúdo de clorofila, por meio de um mecanismo não conhecido (Reddy et al., 2004). King et al. (2001) verificaram que a aplicação de glifosate em doses elevadas (5 a $8,4 \mathrm{~kg} \mathrm{ha}^{-1}$ do produto comercial) diminuiu o crescimento radicular e a nodulação da soja RR. Bott et al. (2008) também constataram redução na MMS de raiz da cultivar Valiosa RR quando tratada com glifosate, relatando ainda que a morfologia da raiz foi alterada, o que causou declínio no alongamento e redução no desenvolvimento das raízes laterais. No entanto, comentam que, no estudo, em concentração insuficiente de Mn na solução, a redução da MMS radicular não ocorreu, alegando que a conversão enzimática do glifosate em AMPA em soja transgênica requer certo nível externo de Mn. Todavia, no presente estudo, a redução da MMS radicular foi independente da concentração de Mn empregado na solução. Oliveira Jr. et al. (2008) encontraram redução na produção de MMS de raiz; das cultivares estudadas com aplicação única de glifosate (900 $\mathrm{g} \mathrm{ha}^{-1}$ e.a.), Valiosa RR foi uma das que apresentaram essa redução. Zobiole et al. (2009) observaram que, independentemente do manejo de aplicação do glifosate, tanto a produção de matéria seca da parte aérea quanto a da raiz foram reduzidas em cultivares transgênicas.

A eficiência de absorção (EA) de Mn foi alterada apenas pelas concentrações de Mn na solução $(\mathrm{p}<0,0001)$, não sendo modificada, portanto, pela introdução do gene de resistência a glifosate nem pela aplicação do herbicida à cultivar transgênica (Figura 3). Verificou-se que a EA das cultivares aumentou com a concentração de Mn, porém, mesmo ocorrendo somente efeito principal de doses, achou-se conveniente apresentar os comportamentos de cada tratamento (Figura 3). O aumento da EA com as concentrações de Mn seria de se esperar, pois, à medida que há maior disponibilidade do elemento na solução, maior quantidade do nutriente pode ser absorvida por unidade de comprimento (ou massa) de raízes. Vale ressaltar ainda que, mesmo com menor produção de matéria seca de raízes (Figura 2b), a cultivar transgênica, quando recebeu aplicação de glifosate, foi eficiente na absorção do Mn. Assim, a raiz afetada pelo herbicida supriu adequadamente com $\mathrm{Mn}$ as demais partes da planta, sem prejudicar a massa de matéria seca total. Nesse caso, não houve alteração no transporte do elemento, que, teoricamente, poderia ter sido imobilizado pela formação de complexos entre o glifosate e o micronutriente $\mathrm{Mn}$, conforme relatado por Eker et al. (2006) e Neumann et al. (2006).

Com o aumento da dose de herbicida, não se observou comportamento diferenciado da cultivar Valiosa $R R$ quanto aos parâmetros $K_{m}, V_{\text {máx }}$ e $C_{\text {mín. }}$. A análise de variância não evidenciou efeito significativo do glifosate na absorção do Mn pela cultivar Valiosa RR, independentemente da dose

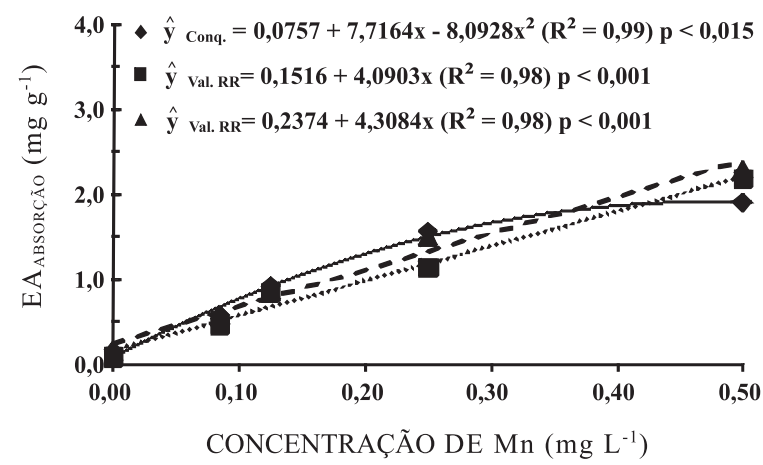

Figura 3. Eficiência de absorção (EA) de Mn das cultivares Conquista e Valiosa RR com e sem aplicação de glifosate via foliar, em função de doses de Mn na solução nutritiva. 
utilizada $\left(\mathrm{P}_{\mathrm{Km}}>0,69 ; \mathrm{P}_{\mathrm{VMax}}>0,83 ; \mathrm{P}_{\text {Cmín }}>0,07\right)$. No quadro 1 estão representados os valores médios dos parâmetros cinéticos. Os valores de $\mathrm{K}_{\mathrm{m}} \mathrm{e} \mathrm{C}_{\text {mín }}$ foram maiores e o de $\mathrm{V}_{\text {máx }}$, menor, que aqueles encontrados por Lavres Junior (2007) para Mn em soja, porém a variedade era diferente, assim como algumas condições experimentais. As implicações práticas dos valores

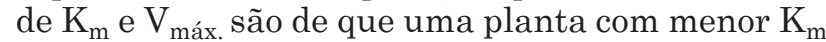
seria mais eficiente na absorção de determinado nutriente quando em baixa disponibilidade. Já uma planta que apresente maior $\mathrm{V}_{\text {máx }}$ é mais eficiente na absorção numa condição de elevada disponibilidade do nutriente. Em termos práticos, plantas com maior $\mathrm{V}_{\text {máx }}$ e menor $\mathrm{K}_{\mathrm{m}}$ são comparativamente superiores, tanto em alta quanto em baixa disponibilidade do nutriente na solução em que a planta esteja inserida. Como esses parâmetros não foram alterados pela aplicação do herbicida, pode-se inferir que este não estaria alterando a absorção do nutriente pela soja e, portanto, seu uso não implicaria modificação da recomendação de adubação, como havia sido observado (Zobiole et al., 2009).

A concentração mínima $\left(\mathrm{C}_{\text {mín }}\right)$ (Quadro 1$)$ corresponde à concentração de $\mathrm{Mn}$ na solução na qual o influxo se iguala ao efluxo (Claassen \& Barber, 1974), ou seja, o influxo líquido é igual a zero. A concentração mínima de Mn a partir da qual existe influxo líquido do nutriente não foi alterada pelos tratamentos.

\begin{tabular}{|c|c|c|}
\hline \multicolumn{3}{|c|}{$\begin{array}{l}\text { Quadro 1. Valores médios dos parâmetros cinéticos } \\
\mathrm{K}_{\mathrm{m}} \text {, velocidade máxima }\left(\mathrm{V}_{\text {máx }}\right) \text { e concentração } \\
\text { do } \mathrm{C}_{\text {mín da cultivar Valiosa } \mathrm{RR} \text { submetida a }} \\
\text { aplicações de glifosate via foliar }\end{array}$} \\
\hline $\mathbf{K}_{\mathrm{m}}$ & $\mathbf{C}_{\text {min }}$ & $V_{\text {máx }}$ \\
\hline \multicolumn{2}{|c|}{$-\mu \mathrm{mol} \mathrm{L}^{-1}$} & $\mu \mathrm{mol} \mathrm{g}{ }^{-1} \mathrm{~h}^{-1}$ \\
\hline 3,04 & 1,81 & 0,36 \\
\hline
\end{tabular}

\section{CONCLUSÕES}

1. A inclusão do gene de resistência ao glifosate não altera a nutrição mangânica na cultivar Valiosa $\mathrm{RR}$, bem como não interfere na produção de matéria seca da planta.

2. Mesmo sendo responsável pela redução da massa de matéria seca radicular, o glifosate não provoca efeito depressivo na absorção e no transporte de Mn na planta de soja geneticamente modificada.

3. Os parâmetros cinéticos de absorção $\mathrm{K}_{\mathrm{m}}, \mathrm{V}_{\text {máx. }}$ e $\mathrm{C}_{\text {mín }}$ não são alterados pelo glifosate aplicado via foliar em uma variedade de soja resistente ao herbicida.

\section{AGRADECIMENTOS}

À Fapesp, pelo suporte financeiro e pela bolsa concedida ao primeiro autor. Ao professor Dr. Luis Vitor Silva do Sacramento, pelo auxílio no estudo da cinética de absorção.

\section{LITERATURA CITADA}

BOTT, S.; TESFAMARIAM, T.; CANDAN, H.; CAKMAK, I.; ROMHELD, V. \& NEUMANN, G. Glifosate induced impairment of plant growth and micronutrient status in glifosate- resistant soybean (Glycine $\max$ L.). Plant Soil, 312:185-194, 2008

BROCH, D.L. \& RANNO, S.K. Fertilidade do solo, adubação e nutrição da cultura da soja. In: Fundação MS, Tecnologia de produção de soja e milho 2008/2009. Maracaju, 2008. p.5-36.

CLAASSEN, N. \& BARBER, S.A. A method for characterizing the relation between nutrient concentration and flux into roots of intact plants. Plant Physiol., 54:564-568, 1974.

CORREIA, N.M. \& DURIGAN, J.C. Seletividade de diferentes herbicidas à base de glifosate a soja RR. Planta Daninha, 25:375-379, 2007.

COUTINHO, C.F.B. \& MAZZO, L.H. Complexos metálicos com o herbicida glifosato: Revisão Química Nova. 28: 1038. 1045, 2005.

DECHEN, A.R. \& NACHTIGALL, G.R. Micronutrientes. In: FERNADES, M.S., ed. Nutrição mineral de plantas. Viçosa, MG, Sociedade Brasileira de Ciência do Solo, 2006. p.328-352.

EKER, S.; OZTURK, L.; YAZICI, A.; ERENOGLU, B.; ROMHELD, V. \& CAKMAK, I. Foliar-applied glifosate substantially reduced uptake and transport of iron and manganese in sunflower (Helianthus annuus L.) plants. J. Agric. Food Chem., 54:10019-10025, 2006.

FEHR, W.R. \& CAVINESS, C.E. Stage of soybean development. Ames, Iowa States University of Sciences and Technology, 1977. 11p. (Special Report, 80)

FENG, P.C.C.; CHIU, T. \& SAMMONS, R.D. Glifosate efficacy is contributed by its tissue concentration and sensitivity in velvetleaf (Abutilon theophrasti). Pestic. Biochem. Physiol., 77:83-91, 2003.

FRANZ, J.E.; MAO, M.K. \& SIKORSKI, J.A. Glifosate: A unique global herbicide. Washington, DC, American Chemical Society, 1997. (ACS Monograph, 189)

GORDON, B. Manganese nutrition of glifosate-resistant and conventional soybeans. Better Crops, 91:12-13, 2007.

HEENAN, D.P. \& CARTER, O.G. Tolerance of soybean cultivars to manganese toxicity. Crop Sci., 16:391-391, 1976. 
HOAGLAND, D.R. \& ARNON, D.I. The water-culture method for growing plants without soil. Berkeley, Califórnia Agricultural Experiment Station, 1850. 32p. (Circ., 347)

HOAGLAND, R.E. Effects of glyfosate on metaboloism of phenolics compounds: VI. Effects of glyfhosine and glifosate metabolites on phenylalanine ammonia-lyase activity, growth and protein, chlorophyll, and anthocyanin levels in soybean (Glycine max) seedlings. Weed Sci., 28:393-400, 1980.

HUBER, D.M. What about glifosate-induced manganese deficiency? Fluid J., 20-22, 2007. Disponível em: www.fluidfertilizer.com/PastArt/pdf/58P20-22.pdf. Acesso em: 18 mar. 2008.

INTERNATIONAL SERVICE FOR THE ACQUISITION OF AGRI-BIOTECH APPLICATIONS AGROBIO. TECNOLOGIA - ISAAA. Resumo executivo - BRIEF 41 - Situação global das culturas biotecnológicas/GM comercializadas: 2009. Disponível em: www.isaaa.org. Acesso em: 14 jan. 2010.

KABACHNIK, M.I.; MEDVED, T.Y.; DYATLOVA, N.M. \& RUDOMINO, M.V Organophosphorus complexones. Russian Chem. Rev., 43:733-744, 1974.

KING, C.A.; PURCEL, L.C. \& VORIES, E.D. Plant growth and nitrogenase activity of glifosate tolerant soybean in response to foliar glifosate applications. Agron. J., 93:179$186,2001$.

LAVRES JUNIOR, J. Influência genotípica na absorção, utilização e na toxidez de manganês na soja. Piracicaba, Centro de Energia Nuclear na Agricultura, Universidade de São Paulo, 2007. 88p. (Tese de Doutorado)

MALAVOLTA, E.; CABRAL, C.P. \& LAVRES Jr., O.A.J. Efeitos do manganês sobre a soja cultivada em solo de Cerrado do triângulo mineiro. Pesq. Agropec. Bras., 35:1629-1636, 2000 .

MALAVOLTA, E.; VITTI, G.C. \& OLIVEIRA, S.A. Avaliação do estado nutricional das plantas: Princípios e aplicações. 2.ed. Piracicaba, Potafos, 1997. 319p.

MARSCHNER, H. Mineral nutrition of higher plants. 2.ed. Londres, Academic Press, 1995. 889p.

NEUMANN, G.; KOHLS, S.; LANDSBERG, E.; STOCKOLIVEIRA SOUZA, K.; YAMADA, T. \& RÖMHELD, V. Relevance of glifosate transfer to non-target plants via rhizosphere. J. Plant Dis. Protec., 118:936-969, 2006.
OLIVEIRA JR., R.S.; DVORANEN, E.C.; CONSTANTIN, J.; CAVALIERI, S.D.; FRANCHINI, L.H.M.; RIOS, F.A. \& BLAINSKI, E. Influência do glifosate sobre a nodulação e o crescimento de cultivares de soja resistente ao glifosate. Planta Daninha, 26:831-843, 2008.

REDDY, K.N.; RIMANDO, A.M. \& DUKE, S.O. Aminomethylphosphonic acid, a metabolite of glifosate, causes injury in glifosate treated, glifosate-resistant soybean. J. Agric. Food Chem., 52:5139-5143, 2004.

REDDY, K.N. \& ZABLOTOWICZ, R.M. Glifosate-resistant soybean response to various salts of glifosate and glifosate accumulation in soybean nodules. Weed Sci., 51:496-502, 2003.

RÖMHELD, V; GULDNER, G.;YAMADA, T.; OZTURK, L.; CAKMAK, I. \& NEUMANN, G. Relevance of glyphosate in the rhizosphere of non-target plants in orchards for plant health. In: LI, C.J.; ZHANG. F.S.; DOBERMANN, A.; HINSINGER, P.; LAMBERS, H.; LY, X.L.; MARSCHNER, P.; MAENE, L.; McGRATH, S.; OENEMA, O.; PENG, S.B.; RENGEL, Z.; SEN, Q.R.; WELCH, R.; WIREN N.; YAN, X.L. \& ZHU, Y.G., eds. Plant nutrition for food security, human health and environment protection. Beijing, Tsinghua University Press, 2005, p. 476-477.

ROSOLEM, C.A.; ANDRADE, G.J.M.; LISBOA, I.P. \& ZOCA, S.M. Manganese uptake and redistribution in soybeans as affected by glifosate. R. Bras. Ci. Solo, 34:1915-1922, 2010 .

RUIZ, H.A. Estimativa dos parâmetros cinéticos $\mathrm{K}_{\mathrm{m}} \mathrm{e} \mathrm{V}_{\text {máx }}$ por uma aproximação gráfico-matemática. R. Ceres, 32:7984, 1985.

SANTOS, J.B.; FERREIRA, E.A.; REIS, M.R.; SILVA, A.A.; FIALHO, C.M.T. \& FREITA, M.A.M. Avaliação de formulações de glifosate sobre soja Roundup Ready. Planta Daninha, 25, 1:165-171, 2007.

WONG, P.K. Effects of 2,4-D glyfosate and paraquat on growth, photosynthetic an chlorophyll-a synthesis of Scenedesmus quadricauda, Berb 614. Chemosphere, 41:177-182, 2002.

ZOBIOLE, L.H.S.; OLIVEIRA JR, R.S.; HUBER, D.M.; CONSTANTIN, J.; CASTRO, C.; OLIVEIRA, F.A. \& OLIVEIRA JR., A. Glifosate reduces shoot concentrations of mineral nutrients in glifosate-resistant soybeans. Plant Soil, 328:57-69, 2009. 